\title{
Protective attenuated lentivirus immunization induces SIV-specific T cells in the genital tract of rhesus monkeys
}

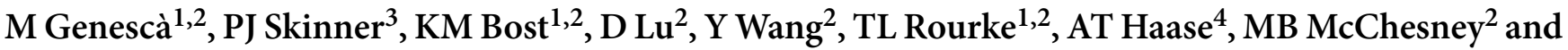 \\ CJ Miller $1,2,5,6$
}

Live attenuated lentivirus immunization is the only vaccine strategy that elicits consistent protection against intravaginal challenge with pathogenic simian immunodeficiency virus (SIV). To determine the mechanism of protection in rhesus monkeys infected with attenuated simian-human immunodeficiency virus (SHIV)89.6, a detailed analysis of SIV Gagspecific T-cell responses in several tissues including the genital tract was performed. Six months after SHIV infection, antiviral T-cell responses were rare in the cervix; however, polyfunctional, cytokine-secreting, and degranulating SIV Gag-specific CD4 ${ }^{+} \mathrm{T}$ cells were consistently found in the vagina of the immunized macaques. SIV-specific CD8 ${ }^{+} \mathrm{T}$ cells were also detected in the vagina, blood, and genital lymph nodes of most of the animals. Thus, an attenuated SHIV vaccine induces persistent antiviral T cells in tissues, including the vagina, where these effector T-cell responses may mediate the consistent protection from vaginal SIV challenge observed in this model.

\section{INTRODUCTION}

It is clear from recently halted human immunodeficiency virus (HIV) vaccine trials that a better understanding of the immune mechanisms necessary to block HIV transmission and control viral replication is critical to the rationale design of HIV vaccines. In the non-human primate models of acquired immune deficiency syndrome, only attenuated lentivirus infection consistently induces protective immunity against vaginal challenge with pathogenic simian immunodeficiency virus (SIV). Understanding the mechanisms of protection elicited by this immunization strategy may facilitate design of an effective HIV vaccine. ${ }^{1,2}$ Systemic, intranasal, or genital immunization with virulence-attenuated simian-human immunodeficiency virus (SHIV) 89.6 protects $60 \%$ (30 out of 48 ) of rhesus monkeys from uncontrolled viral replication for 6 months after vaginal challenge with SIVmac239. ${ }^{3,4}$ Due to the lack of homology in the envelope of the immunizing and challenge viruses, neutralizing antibody can be ruled out as the mechanism of protection in this model, and a critical role for cytotoxic $\mathrm{T}$ lymphocytes has been proposed. ${ }^{3,4}$
The distribution of immune cells in the reproductive tract of women and female rhesus macaques is similar. ${ }^{5}$ Both $\mathrm{CD}^{+}$and $\mathrm{CD} 8^{+} \mathrm{T}$ cells are found in the lamina propia and epithelium of the vagina and cervix. ${ }^{6} \mathrm{CD} 8{ }^{+} \mathrm{T}$ cells are especially abundant in the deep layers of the vaginal epithelium and lamina propia of rhesus macaques. In both acute and chronic SIV infection, specific CD8 ${ }^{+}$cytotoxic $\mathrm{T}$ lymphocytes are found in the vaginal mucosa ${ }^{7,8}$ of rhesus macaques, and anti-HIV cytotoxic T lymphocytes are also present in the cervical mucosa of HIV-1-infected women. ${ }^{9}$ $\mathrm{CD}^{+}{ }^{+} \mathrm{T}$-cell responses are detectable in the genital tract tissues about 14 days after SIV inoculation, but this is 7 days after systemic infection is established, ${ }^{8}$ and widely disseminated antiviral T-cell responses are not detectable until 28 days post-inoculation. Thus, an effective vaccine-induced, mucosal memory T-cell response at the portal of entry could contain viral replication in the genital tract and prevent the establishment of a systemic infection. ${ }^{10}$ Although mucosal immune responses are thought to be desirable, to date, there have been no reports of antiviral T cells in the genital tract of rhesus mon-

\footnotetext{
${ }^{1}$ Center for Comparative Medicine, University of California, Davis, California, USA. ${ }^{2}$ California National Primate Research Center, University of California, Davis, California, USA. ${ }^{3}$ Department of Veterinary and Biomedical Sciences, University of Minnesota, St Paul, Minnesota, USA. ${ }^{4}$ Department of Microbiology, University of Minnesota, St Paul, Minnesota, USA. ${ }^{5}$ Department of Pathology, Microbiology and Immunology, School of Veterinary Medicine, University of California, Davis, California, USA. 6Division of Infectious Diseases, School of Medicine, University of California, Davis, California, USA. Correspondence: CJ Miller (cjmiller@ucdavis.edu) 


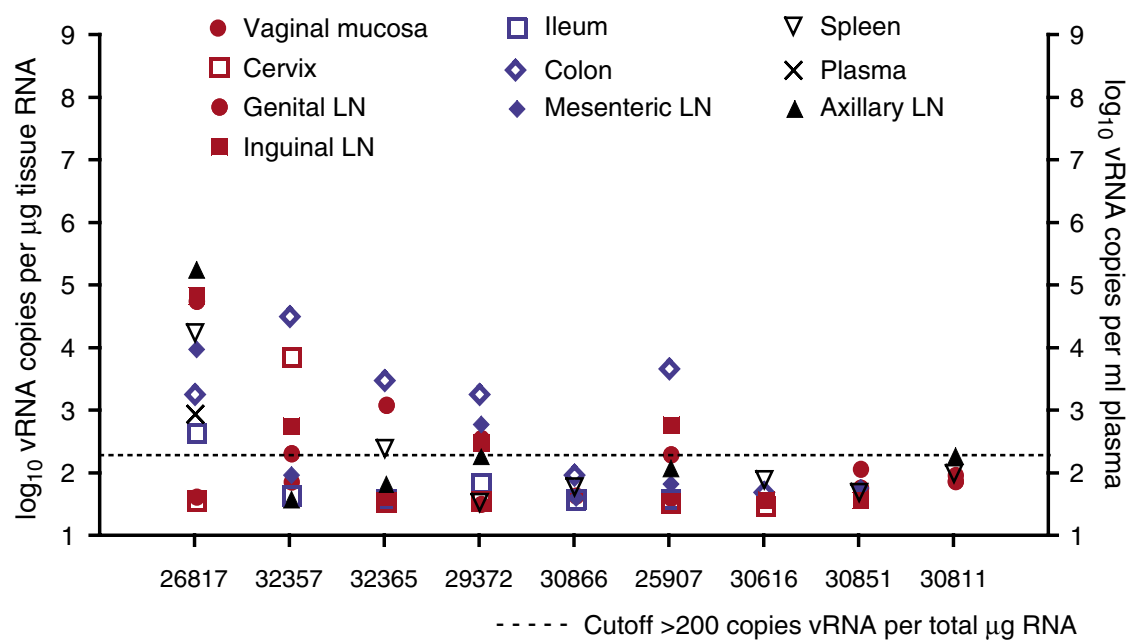

Figure 1 SHIV89.6 vRNA levels in plasma and tissues of vaccinated rhesus macaques 6-8 months after immunization. Plasma vRNA levels are expressed as $\log _{10}$ vRNA copies per ml of plasma and tissue vRNA levels are expressed as $\log _{10}$ vRNA copies per $\mu \mathrm{g}$ of total tissue RNA. Each symbol represents a tissue in one of three different compartments: genital tract (red symbols); gastrointestinal tract (blue symbols); and systemic tissues (black symbols). The dotted horizontal line indicates a cutoff of 200 copies per $\mu \mathrm{g}$ tissue RNA as the limit of quantitation for tissue vRNA (see Methods). SHIV, simian-human immunodeficiency virus; vRNA, viral RNA.

keys immunized with an acquired immune deficiency syndrome vaccine candidate.

To determine if attenuated SHIV immunization elicits an SIV-specific T-cell response in the female genital tract, nine rhesus macaques were necropsied 6-8 months after SHIV89.6 immunization and the functional capacity of Gag-specific T-cell responses in tissues, including the genital tract, was assessed. We found anti-SIV CD8 ${ }^{+} \mathrm{T}$-cell responses in the vagina of most SHIV-immunized animals. More consistently, a pool of effector-memory SIV-specific $\mathrm{CD} 4^{+} \mathrm{T}$ cells capable of degranulating and producing interleukin 2 (IL-2) was present in the vagina of all SHIV-immunized animals. Importantly, antiviral T-cell responses were rare in the cervix. Further, the functional phenotype of anti-SIV T-cell responses in peripheral blood mononuclear cells (PBMCs) did not reflect the T-cell responses observed in the vagina. In summary, a persistent, SIV-specific effectormemory T-cell response was established in the vagina during attenuated lentivirus infection.

\section{RESULTS}

\section{Virology of attenuated SHIV89.6 infection}

Nine female rhesus macaques were intravenously inoculated with SHIV89. $6^{11}$ and 2 weeks later, all the animals had peak plasma viral RNA (vRNA) levels of approximately $10^{6} \mathrm{vRNA}$ copies per $\mathrm{ml}$, which rapidly dropped by 6 weeks post-SHIV infection (data not shown). By the time of necropsy, at 6-8 months post-SHIV infection, all the animals had undetectable levels of plasma vRNA except animal 26817, which had 2,095 copies per $\mathrm{ml}$ and 899 copies per $\mathrm{ml}$ of vRNA in plasma at 31 and 33 weeks post-inoculation, respectively. It is worth noting that 26817 was also the only monkey, in the group of nine animals, that had $>10^{4} \mathrm{vRNA}$ copies per ml plasma at 6 weeks post-inoculation.

Variable, but low, levels of vRNA were detected in the tissues analyzed (genital tract, gastrointestinal tract, and lymphoid tissues) at necropsy (Figure 1). In animals 30886, 30616 , and 30851, no vRNA was detected by quantitative branched DNA assay in any of the tissues analyzed. Animal 26817, the only animal with virus detectable in plasma at necropsy, had vRNA levels exceeding $10^{4} \mathrm{vRNA}$ copies per $\mu \mathrm{g}$ tissue RNA in the genital, inguinal, and axillary lymph nodes. Finally, monkey 32357 had $>10^{4} \mathrm{vRNA}$ copies per $\mu \mathrm{g}$ tissue RNA in the colon. Indeed, of the animals that had detectable tissue SHIV vRNA, the colon was the tissue that was most often positive.

To confirm the attenuated nature of the SHIV infection, peripheral $\mathrm{CD} 4{ }^{+} \mathrm{T}$ counts were monitored. No significant changes were observed in the absolute number of $\mathrm{CD}^{+}$or $\mathrm{CD}^{+} \mathrm{T}$ cells in blood of any animal over the immunization period (data not shown). As with uninfected monkeys, memory $\mathrm{CD}^{+}{ }^{+} \mathrm{T}$ cells $\left(\mathrm{CD}^{+} / \mathrm{CD}^{+} / \mathrm{CD}^{+} 5^{+}\right)$constituted between 70 and $80 \%$ of the total $\mathrm{CD}^{+}{ }^{+} \mathrm{T}$ cells in the SHIV-infected monkeys at 6-8 months post-inoculation. By the time of necropsy, two SHIV-infected animals, 26817 and 25907, had a fivefold increased frequency of peripheral $\mathrm{CD} 4^{+} / \mathrm{CCR} 5^{+} \mathrm{T}$ cells relative to pre-infection. The remaining seven SHIV-infected animals had a one- to twofold increase in $\mathrm{CD} 4^{+} / \mathrm{CCR}^{+} \mathrm{T}$-cell frequency compared to pre-infection (data not shown).

\section{Intravenous SHIV immunization induced memory SIV Gag-specific T cells in the vagina}

To assess SIV-specific T-cell responses in the genital tract, lymphocytes were isolated from fresh cervix and vagina by mechanical disruption and enzymatic digestion as described. ${ }^{12}$ Mononuclear cells were isolated on a Percoll gradient, resuspended in RPMI-1,640 medium with $10 \%$ fetal calf serum, and incubated overnight. Using this strategy, $4-27 \times 10^{6}(13.1 \pm 2.7$, mean \pm s.e.m.; $n=9)$ mononuclear cells were isolated from the vagina, and $2-19 \times 10^{6}(8.2 \pm 1.9 ; n=9)$ mononuclear cells were isolated from the cervix. Analyses were performed separately for the vaginal mucosa and the cervix. From each tissue, $5 \times 10^{5}$ fresh 
a

a Vagina: $\mathrm{CD}^{+} \mathrm{T}$ cells

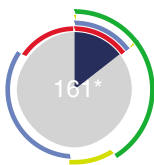

26817

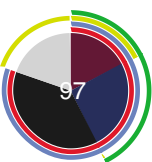

32357

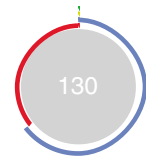

32365

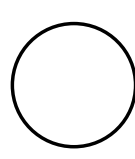

30866

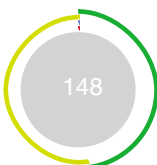

25907

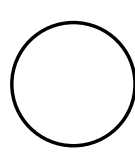

30616

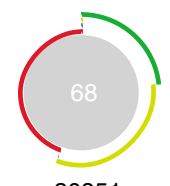

30851

b Vagina: $\mathrm{CD} 4^{+} \mathrm{T}$ cells

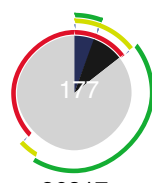

26817

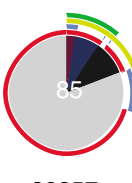

32357

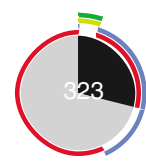

32365

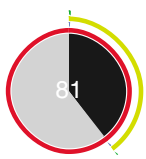

30866

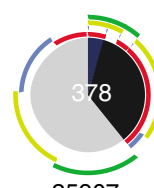

25907

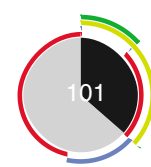

30616

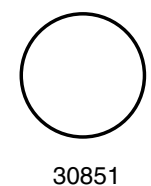

c Cervix: $\mathrm{CD}^{+} \mathrm{T}$ cells

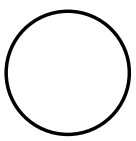

26817

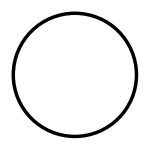

30866

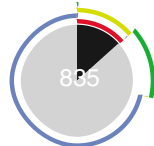

25907

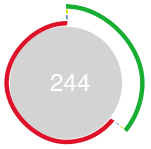

30616

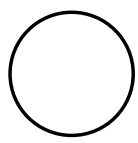

30851

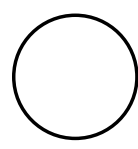

30811

d Cervix: $\mathrm{CD}^{+} \mathrm{T}$ cells

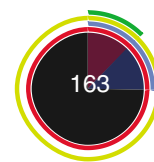

26817

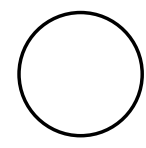

30866

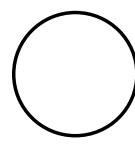

25907

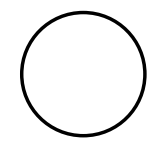

30616

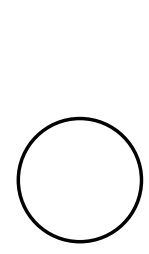

30851

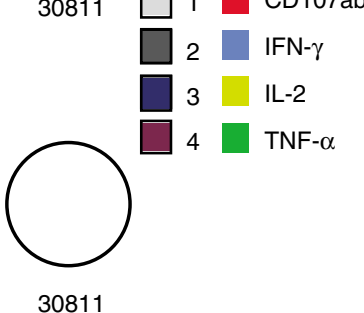

Figure 2 Frequency and functional capacity of SIV Gag-specific T cells in the genital tract of SHIV89.6-immunized rhesus macaques. SIV-specific $\mathrm{CD}^{+}(\mathbf{a})$ and $\mathrm{CD}^{+}(\mathbf{b})$ T-cell responses in freshly isolated vaginal mononuclear cells from each of the seven animals analyzed are shown as pie charts (samples from two animals were not analyzed because there were $<3,000$ events in the CD3 ${ }^{+} \mathrm{CD} 8^{+} \mathrm{T}$-cell gate). SIV-specific CD8 ${ }^{+}$(c) and $\mathrm{CD}^{+}$(d) T-cell responses in freshly isolated cervical mononuclear cells from each of the six animals analyzed are shown as pie charts (samples from two animals were not analyzed because there were $<5,000$ events in the CD3 ${ }^{+}$T-cell gate and the sample from another animal was not analyzed because there were $>1,000$ more events in the p27-stimulated tube relative to the background tube). Empty circles indicate that there was no positive response in the indicated T-cell subset in that sample. ${ }^{*}$ For every positive response, the frequency of positive SIV-specific T cells was normalized to $10^{5}$ $\mathrm{CD}^{+} \mathrm{T}$ cells and this value is shown in white at the center of the pie chart. Each colored portion of a pie chart indicates the percentage of SIV-specific T cells that responded with one, two, three, or four functions, and the arcs around the pie show the function or combination of functions to which the specific response corresponds (see color legend). Animal number indicated below each Pie chart. SHIV, simian-human immunodeficiency virus; SIV, simian immunodeficiency virus.

cells were stimulated with a Gag p27 peptide pool in an intracellular cytokine assay as previously described ${ }^{13}$ to determine CD107a and CD107b mobilization (degranulation), interferon $\gamma$ (IFN- $\gamma$ ), tumor necrosis factor- $\alpha$ (TNF- $\alpha$ ), and IL-2 production. From the original $5 \times 10^{5}$ fresh cells, all the events in the lymphocyte gate based on forward vs. side scatter (FSC/SSC) were acquired, which corresponded to between 40,000 and 100,000 lymphocytes in the vagina and between 10,000 and 30,000 lymphocytes in the cervix. Thus, based on FSC/SSC gating, 20\% of the total mononuclear cells in the vaginal-cell suspension were gated lymphocytes, $\sim 60 \%$ of gated lymphocytes were $\mathrm{CD}^{+} / 7$ $\mathrm{AAD}^{-}$live $\mathrm{T}$ cells, and $>25 \%$ of the $\mathrm{CD}^{+} / 7-\mathrm{AAD}^{-} \mathrm{T}$ cells were $\mathrm{CD}^{+}{ }^{+}$and $>50 \%$ were $\mathrm{CD} 8{ }^{+}$. However, in the cervix cell suspension, approximately $15 \%$ of the total mononuclear cells were lymphocytes based on FSC/SSC gating, while $~ 30 \%$ of the gated lymphocytes were $\mathrm{CD}^{+} / 7-\mathrm{AAD}^{-}$live $\mathrm{T}$ cells, and $\sim 25 \%$ of the $\mathrm{CD}^{+} / 7-\mathrm{AAD}^{-} \mathrm{T}$ cells were $\mathrm{CD} 4^{+}$and $\sim 60 \%$ were $\mathrm{CD} 8^{+}$. Samples with less than $5,000 \mathrm{CD}^{+} / 7-\mathrm{AAD}^{-} \mathrm{T}$ cells, and/or less than $3,000 \mathrm{CD}^{+} / 7-\mathrm{AAD}^{-}$events, were excluded from the analyses. Further, samples that had a large discrepancy between the number of events in the dimethyl sulfoxide (DMSO) control and the p27-stimulated tubes were eliminated. The relatively low yield of viable lymphocytes isolated from fresh tissues was a primary consideration in designing these experiments. The results are reported as the number of responding $\mathrm{CD} 4^{+}$or $\mathrm{CD} 8^{+}$ T cells per $10^{5} \mathrm{CD}^{+}$lymphocytes rather than the percentage of responding T cells. Although CD4/CD8 double-positive $\mathrm{T}$ cells with a polyfunctional phenotype are common in rhesus monkeys, ${ }^{14}$ the mucosal and systemic SIV-specific $\mathrm{CD} 4{ }^{+} \mathrm{T}$ cells described in this report were not $\mathrm{CD}^{+}$.

Five out of seven animals analyzed had $\mathrm{CD} 8^{+} \mathrm{T}$ cells in the vagina $\left(120 \pm 17\right.$ anti-SIV $\mathrm{CD} 8^{+} / 10^{5} \mathrm{CD}^{+} \mathrm{T}$ cells; mean \pm s. e.m.; $n=5$ ) that secreted cytokines or degranulated in response to SIV Gag peptide stimulation. This response was composed of a variety of monofunctional SIV-specific $\mathrm{CD}^{+}{ }^{+} \mathrm{T}$ cells but IFN- $\gamma$ secretion was not a dominant feature of the $\mathrm{CD} 8^{+}$ 
T-cell response in the vagina (Figure 2a). It is worth noting that two animals (26817 and 32357) had polyfunctional SIV-specific $\mathrm{CD} 8^{+} \mathrm{T}$ cells in the vagina. Anti-SIV $\mathrm{CD} 4^{+} \mathrm{T}$ cells were found in the vagina $\left(191 \pm 53 \mathrm{CD}^{+}\right.$per $10^{5} \mathrm{CD}^{+} \mathrm{T}$ cells; $\left.n=6\right)$ of six out of seven animals analyzed, with a high proportion of $\mathrm{CD} 107^{+}$and IL-2 ${ }^{+}$cells among the SIV-specific CD4 ${ }^{+}$T-cell pool (Figure 2b). Furthermore, a fraction of the anti-SIV CD107 ${ }^{+}$ $\mathrm{CD}^{+} \mathrm{T}$ cells also secreted IL-2 and/or TNF- $\alpha$ (Figure 2b).

In the cervix, only two out of six animals (25907 and 30616; Figure 2c) analyzed had SIV Gag-specific CD8 ${ }^{+}$T-cell responses, and only one out of six (26817; Figure 2d) had an SIV Gag-specific CD4 ${ }^{+}$T-cell response. The SIV-positive T-cell responses in the cervix were variable in the strength and the number of functions performed.

\section{Immunodominant SIV Gag epitope-specific CD8 ${ }^{+} \mathrm{T}$ cells are present in the genital tract and systemic tissues 6 months after SHIV89.6 immunization}

Although we wanted the results of the study to be generally applicable to all major histocompatibility complex (MHC) class I haplotypes, we did include a single $M a m u-A^{\star} 01$ monkey in the study so that minimal peptides and tetramers could be used to track SIV-specific T cells. To assess minimal peptide-specific T-cell responses in the genital tract of the single Mamu- ${ }^{\star} 01$-positive animal present in the study (30851), freshly isolated lymphocytes from vagina were stimulated with an immunodominant Gag peptide epitope restricted by this allele ${ }^{15}$ CM9 (CTPYDINQM, Gag 181-189). A strong SIV-specific $\mathrm{CD} 8{ }^{+} \mathrm{T}$ cell response was found $\left(345\right.$ anti-SIV CD8 ${ }^{+}$cells per $10^{5} \mathrm{CD}^{+} \mathrm{T}$ cells) after CM9 peptide stimulation of vaginal mononuclear cells. The majority of these CM9-specific CD8 ${ }^{+}$ $\mathrm{T}$ cells expressed $\mathrm{CD} 107^{+}$, while fewer $\mathrm{CD} 8^{+} \mathrm{T}$ cells were single TNF- $\alpha^{+}$or TNF- $\alpha^{+} / \mathrm{CD} 107^{+}$. TNF- $\alpha^{+} / \mathrm{IL}-2^{+}$cells were also detected but rare (Figure 3). IFN- $\gamma$ secretion was not detected in response to $\mathrm{CM} 9$ stimulation of vaginal $\mathrm{CD} 8^{+} \mathrm{T}$ cells. It has been previously reported that $\mathrm{CD} 4{ }^{+} \mathrm{T}$ cells can respond to 9-mer peptides ${ }^{16}$ and, in fact, the $M a m u-A^{*} 01^{+}$animal (30851) had CM9-specific $\mathrm{CD} 4^{+} \mathrm{T}$ cells $\left(115 \mathrm{CD} 4^{+}\right.$per $10^{5} \mathrm{CD}^{+}$ $\mathrm{T}$ cells) in the vagina. Similar to the $\mathrm{CD} 4^{+} \mathrm{T}$-cell response to the p27 peptide pool observed in the other animals, $75 \%$ of the anti-SIV-specific $\mathrm{CD} 4^{+} \mathrm{T}$ cells expressed $\mathrm{CD} 107^{+}$, and the rest were IL- ${ }^{+} / \mathrm{CD} 107^{+}$(Figure 3 ). The finding of $\mathrm{CD} 107^{+} \mathrm{SIV}-$ specific $\mathrm{T}$ cells in immunized animals is consistent with a recent report in which induction of $\mathrm{T}$ cells with rapid cytolytic capacity in PBMCs was a feature of live attenuated SIV vaccines. ${ }^{17}$

Tetramer staining of the genital tract cell suspensions demonstrated that $0.48 \%$ of the $\mathrm{CD} 3^{+} \mathrm{CD} 8{ }^{+} \mathrm{T}$ cells in the vagina were CM9 tetramer ${ }^{+}$(Figure 4a). In addition, tetramers incorporating three previously defined $M a m u-\mathrm{A}^{*} 01$-restricted epitopes ${ }^{8}$ (Gag VT10, Tat SL8, and envelope TL9), in addition to the Gag CM9 tetramer, were used to stain cryopreserved cells from axillary lymph nodes, mesenteric lymph nodes, genital lymph nodes, and PBMCs from the only $M a m u-\mathrm{A}^{\star} 01^{+}$monkey in the study. CM9 tetramer-specific CD8 ${ }^{+} \mathrm{T}$ cells were detected in axillary lymph nodes $(0.23 \%)$ and PBMCs $(0.26 \%)$, and SL8specific $\mathrm{CD} 8{ }^{+} \mathrm{T}$ cells were found in the axillary lymph nodes

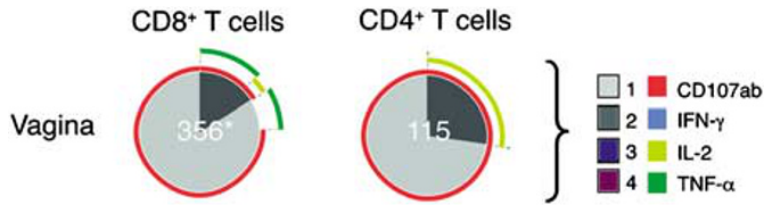

Figure 3 Frequency and distribution of Gag CM9-specific T cells in the vagina 6 months post-SHIV89.6 immunization. SIV-specific CD8 ${ }^{+}$and $\mathrm{CD} 4{ }^{+} \mathrm{T}$-cell responses in freshly isolated vaginal mononuclear cell samples from the Mamu-A*01-positive animal (30851) are shown as a pie chart. The frequency of positive CM9-specific $\mathrm{T}$ cells normalized to $10^{5} \mathrm{CD}^{+} \mathrm{T}$ cells is shown as a white number in the center of the pie chart. Each colored portion of a pie chart indicates the percentage of SIV-specific T cells that responded with one, two, three, or four functions, and the arcs around the pie show the function or combination of functions to which the specific response corresponds (see color legend). ${ }^{*}$ Number of CM9-specific CD8 ${ }^{+}$or $\mathrm{CD} 4^{+} \mathrm{T}$ cells (per $10^{5} \mathrm{CD}^{+} \mathrm{T}$ cells). IFN- $\gamma$, interferon $\gamma$; IL-2, interleukin 2; SHIV, simian-human immunodeficiency virus; SIV, simian immunodeficiency virus; TNF- $\alpha$, tumor necrosis factor- $\alpha$.

(0.46\%) (Figure 4a). These findings were partially confirmed by in situ tetramer staining, as $\mathrm{CM} 9$ tetramer ${ }^{+} / \mathrm{CD} 8^{+} \mathrm{T}$ cells were found in axillary lymph nodes, cervix, and vagina (Figure $4 \mathbf{b}$ ). Thus the CD8 ${ }^{+} \mathrm{T}$-cell responses of the $\mathrm{Mamu}-\mathrm{A}^{*} 01^{+}$monkey were strong, widely disseminated, and polyfunctional.

\section{Intravenous SHIV immunization induced SIV Gag-specific memory T-cell responses in peripheral blood and systemic lymphoid tissues}

On the basis of an enzyme-linked immune spot assay, seven out of eight animals had SIV-specific IFN- $\gamma$-secreting T cells in blood at 8-9 weeks post-SHIV infection and at the end of the immunization period (6-8 months post-inoculation) (Table 1). The strength of the IFN- $\gamma$-secreting T-cell response was not related to the levels of SHIV vRNA in tissues or plasma.

On the basis of the intracellular cytokine staining analyses, most of the animals (eight out of nine animals) had detectable anti-SIV CD8 ${ }^{+}$T-cell responses in PBMCs and genital lymph nodes (seven out of nine animals) at the end of the immunization period; however, there was great variability in the frequency and functional phenotype of the responses in PBMCs and lymph nodes. On the other hand, less than half of the animals had a positive response in the axillary lymph nodes (four out of nine animals) and mesenteric lymph nodes (three out of nine animals) (Figure 5). It is worth noting that this analysis was performed on cryopreserved samples and the CD107ab marker was not used, thus the degranulating capacity of these cells is unknown. In most of the tissues, there was a predominance of monofunctional IFN- $\gamma$-secreting SIV-specific CD8 ${ }^{+} \mathrm{T}$ cells, with fewer polyfunctional anti-SIV CD8 ${ }^{+} \mathrm{T}$ cells. However, there was not a consistent pattern of $\mathrm{CD}^{+} \mathrm{T}$-cell response among the tissues of an individual animal. Both the animal with the highest tissue vRNA levels and the Mamu- $\mathrm{A}^{*} 01^{+}$monkey with undetectable vRNA in all tissues had $\mathrm{CD}^{+} \mathrm{T}$-cell responses in five (PBMCs, axillary lymph nodes, mesenteric lymph nodes, genital lymph nodes, and vagina) of six tissues tested.

SIV Gag peptide-specific CD4 ${ }^{+} \mathrm{T}$-cell responses were also found in at least one tissue of all SHIV-immunized animals 


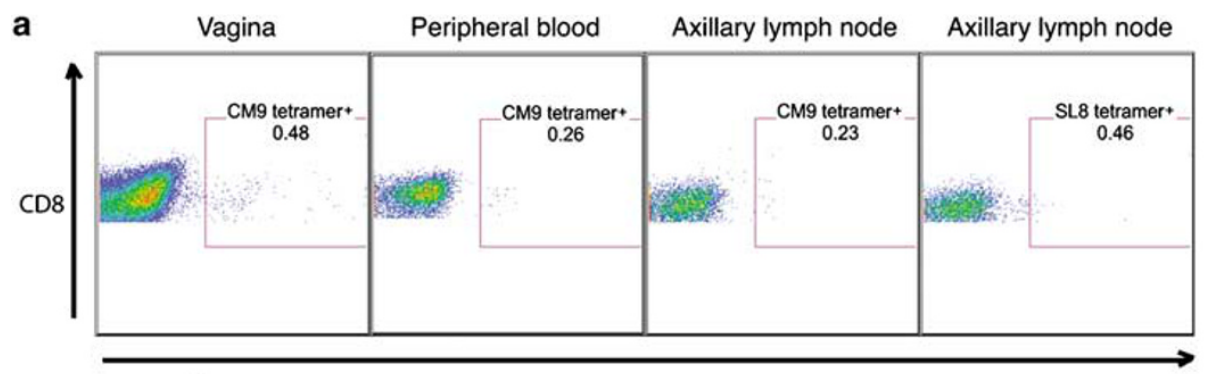

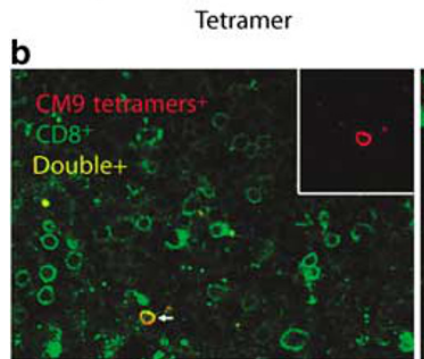

Axillary lymph node

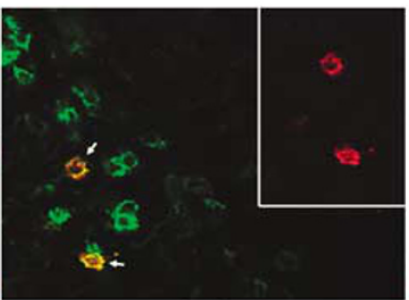

Cervix

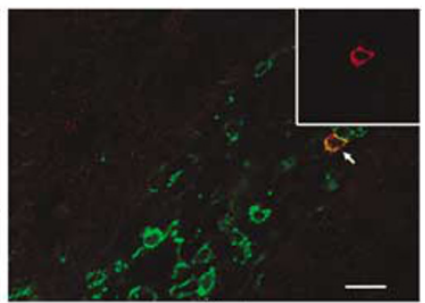

Vagina

Figure 4 Flow cytometry and in situ detection of Mamu $\mathrm{A}^{*} 01 /$ gag tetramer ${ }^{+} \mathrm{CD}^{+} \mathrm{T}$ cells in the genital tract and systemic tissues 6 months after SHIV89.6 immunization. (a) Flow cytometry plots showing the Mamu-A*01 $\mathrm{Gag}_{181-189} \mathrm{CM}$ and Tat ${ }_{28-35}$ SL8 tetramer ${ }^{+} \mathrm{CD}^{+}{ }^{+} \mathrm{T}-\mathrm{cell}$ frequencies in freshly isolated vaginal mononuclear cells and cryopreserved PBMC and axillary lymph node mononuclear cells from animal 30851 . (b) In situ detection of $\mathrm{Mamu} \mathrm{A}^{*} 01 / \mathrm{gag} \mathrm{CM} 9$ tetramer ${ }^{+} \mathrm{CD} 8^{+} \mathrm{T}$ cells in axillary lymph nodes, cervix, and vagina from animal 30851 . Tetramer stain (red, inset), CD8 antibody stain (green), and tetramer and CD8 antibody double-staining cells (yellow) are shown. Arrows indicate tetramer ${ }^{+}$CD8 ${ }^{+}$cells. All images are confocal $z$-scans collected using a $\times 60$ objective lens. The bar $=20 \mu \mathrm{m}$. SHIV, simian-human immunodeficiency virus.

Table 1 Major histocompatibility complex class I haplotype and SIV-specific interferon- $\gamma$-secreting T-cell responses in SHIV89.6-immunized monkeys

IFN- $\gamma$ spot-forming cells per $10^{6}$ mononuclear cells ${ }^{a}$

\begin{tabular}{|c|c|c|c|c|}
\hline Monkey & MHC class I alleles & Acute SHIV ${ }^{b}$ PBMC & Necropsy PBMC & Necropsy spleen \\
\hline 26817 & A08 & 76 & 60 & 65 \\
\hline 32357 & $-^{c}$ & 146 & 30 & 225 \\
\hline 29372 & - & 83 & Negative & Negative \\
\hline 30886 & B01 & 101 & Negative & 35 \\
\hline 30851 & $\mathrm{~A} 01$ & 270 & 165 & 45 \\
\hline 30811 & B01 & $N D^{d}$ & 65 & Negative \\
\hline
\end{tabular}

IFN- $\gamma$, interferon $\gamma$; MHC, major histocompatibility complex; PBMC, peripheral blood mononuclear cell; SHIV, simian-human immunodeficiency virus; SIV, simian immunodeficiency virus.

aA sample was considered positive if the number of IFN- $\gamma$-secreting cells per well exceeded 50 cells per $1 \times 10^{6}$ mononuclear cells and if the number of positive IFN- $\gamma$ spot-forming cells (SFC) was greater than the mean number of SFC found in the medium-only wells plus 2 s.d.. Data are reported as the number of IFN- $\gamma$ SFC per $1 \times 10^{6}$ PBMC. For reporting purposes, the background number of IFN- $\gamma$ SFC observed in medium-only wells was subtracted from the number of IFN- $\gamma$ SFC of SIV peptide-stimulated wells.

bEight to nine weeks post-SHIV89.6 immunization.

cMHC class I loci and alleles were typed by PCR. A dash (-) indicates no known alleles.

dND indicates that a sample was missing or results were not interpretable.

(Figure 6). In all tissues except PBMCs, the SIV-specific CD4 ${ }^{+} \mathrm{T}$ cells produced TNF- $\alpha$ and IL- 2 with few IFN- $\gamma$-secreting T cells. In the PBMCs of three out of the four animals with no detectable tissue vRNA, a large fraction of CD ${ }^{+} \mathrm{T}$ cells was TNF- $\alpha^{+} / \mathrm{IL}-$ $2^{+} / \mathrm{IFN}-\gamma^{+}$simultaneously. Among the nine monkeys studied, the $M a m u-\mathrm{A}^{\star} 01^{+}$animal (30851) had the strongest and the most multifunctional $\mathrm{CD} 4^{+}$- and $\mathrm{CD} 8{ }^{+}$-specific $\mathrm{T}$ responses in all tissues (Figures 5 and 6), including the CM9-specific T-cell response (Figure 7). This may explain why animals with this allele have an inherent ability to control virus replication.

\section{DISCUSSION}

In previous experiments, immunization with virulenceattenuated SHIV89.6 protected $60 \%$ of rhesus monkeys from 


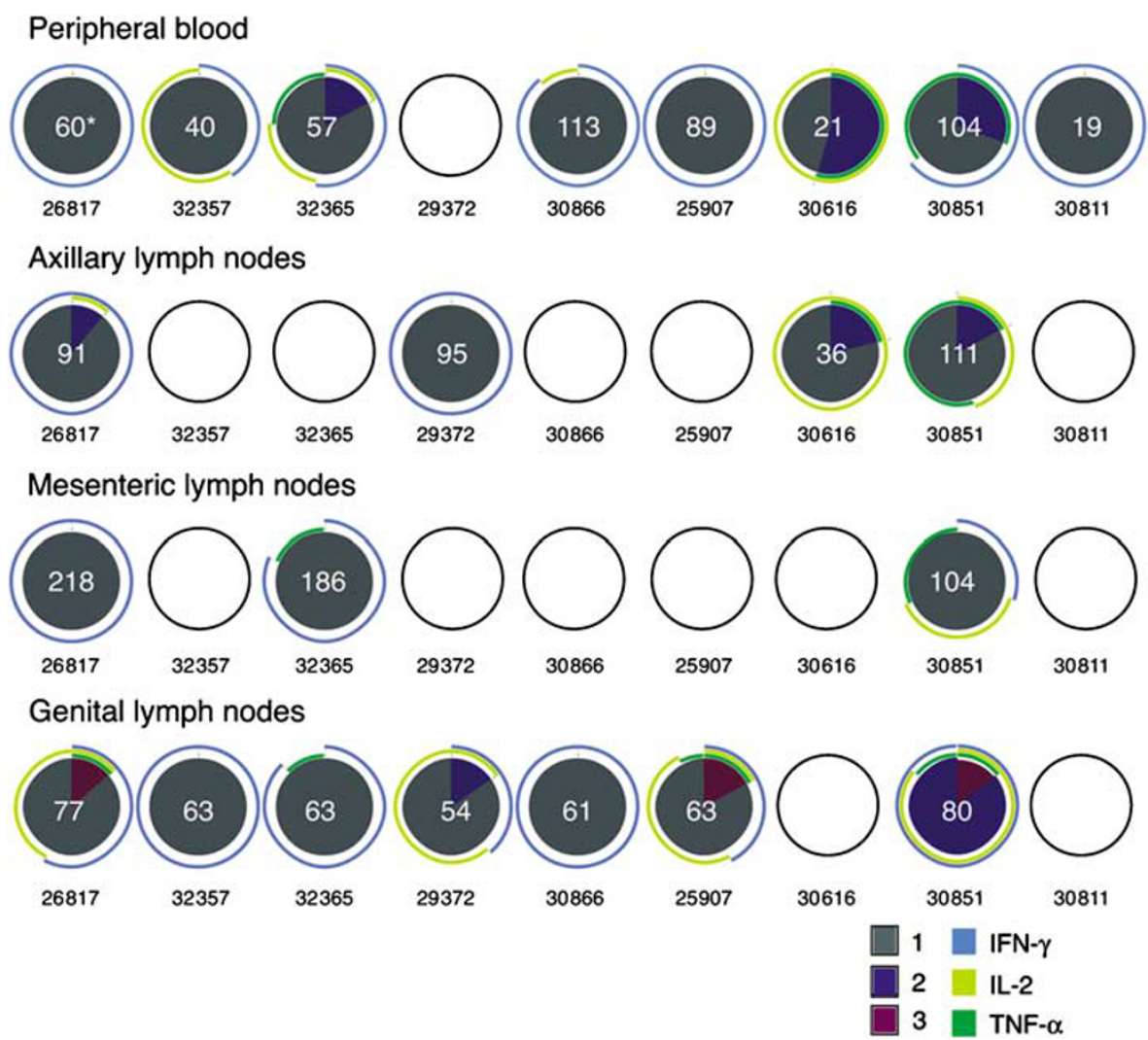

Figure 5 Gag-specific CD8+ T-cell responses in lymphoid tissues and blood of SHIV89.6-immunized rhesus macaques. SIV-specific CD8+ T-cell responses from cryopreserved PBMCs, axillary, mesenteric, and genital lymph node mononuclear cell samples are shown as a pie chart. Empty circles indicate that there was no positive response in the indicated T-cell subset in that sample. For every positive response, the frequency of positive SIVspecific T cells was normalized to $10^{5} \mathrm{CD}^{+} \mathrm{T}$ cells and that value is shown in white at the center of the pie chart. Each portion of a pie chart indicates the percentage of SIV-specific T cells that responded with one, two, or three functions, and the arcs around the pie show the function or combination of functions to which the specific response corresponds (see color legend). ${ }^{*}$ Number of p27-specific CD8 ${ }^{+} \mathrm{T}$ cells (per $10^{5} \mathrm{CD} 3^{+} \mathrm{T}$ cells). IFN- $\gamma$, interferon $\gamma$; IL-2, interleukin 2; PBMC, peripheral blood mononuclear cell; SHIV, simian-human immunodeficiency virus; SIV, simian immunodeficiency virus; TNF- $\alpha$, tumor necrosis factor- $\alpha$.

uncontrolled viral replication for 6 months after vaginal challenge with virulent SIVmac239., Because this is the most reliable protection yet demonstrated against vaginal SIV challenge, defining the immunologic mechanisms responsible for the SHIV89.6-mediated protection is of considerable interest. T-cell responses in tissues, and especially in the genital tract, may more accurately reflect the protective immune responses during acute infection; thus, the major goal of this study was to characterize the genital tract $\mathrm{T}$-cell responses in animals infected with attenuated SHIV89.6 at the time of vaginal challenge. We found that SIV-specific T-cell responses are consistently induced in the genital tract of female rhesus macaques by systemic attenuated lentivirus immunization. SIV Gag-specific polyfunctional $\mathrm{CD} 4{ }^{+} \mathrm{T}$ cells that degranulated and secreted IL- 2 and TNF- $\alpha$ were present in the vagina at $6-8$ months post-immunization in all animals. A more variable, monofunctional $\mathrm{CD} 8{ }^{+} \mathrm{T}$-cell response was also seen in the vagina. These antiviral effectormemory $\mathrm{T}$ cells are present at the portal of entry at the time when SHIV immunization is highly effective against vaginal SIV challenge. ${ }^{3,4}$ To more definitively associate specific T-cell responses with challenge outcome, it would be preferable to challenge the animals after tissue samples were obtained for the determination of T-cell responses. However, because we presume that biopsy lesions of the size and number needed to accurately assess T-cell responses in the vagina and cervix (see Methods) would alter the results of the challenge outcome, longitudinal studies of that nature were not attempted. Therefore, although the evidence is indirect, it seems likely that the antiviral CD8 ${ }^{+}$ $\mathrm{T}$ cells in the genital mucosa contribute to the protective effect of this attenuated lentivirus infection. Anti-SIV T-cell responses were consistently detected in the vagina (anti-SIV CD8 ${ }^{+} \mathrm{T}$-cell responses in five out of seven animals, anti-SIV CD4 ${ }^{+} \mathrm{T}$-cell responses in seven out of seven animals) but they were rare in the cervix (anti-SIV CD8 ${ }^{+} \mathrm{T}$-cell responses in two out of six animals, anti-SIV CD4 ${ }^{+} \mathrm{T}$-cell responses in one out of six animals). Thus, $\mathrm{CD} 8{ }^{+} \mathrm{T}$ cells in the cervix do not seem to be critical for the SHIV89.6-mediated protection from vaginal SIV challenge. In marked contrast, the $60 \%$ rate of protection from vaginal SIV challenge in SHIV-immunized animals closely mirrors the proportion of the SHIV-immunized animals in this study (70\%) that had SIV-specific CD8 ${ }^{+} \mathrm{T}$ cells in the vagina.

$\mathrm{CD}^{+} \mathrm{T}$-cell responses are generally considered an important component of an effective antiviral immune response. In rhesus macaques, short-term depletion of lymphocytes expressing 
Peripheral blood

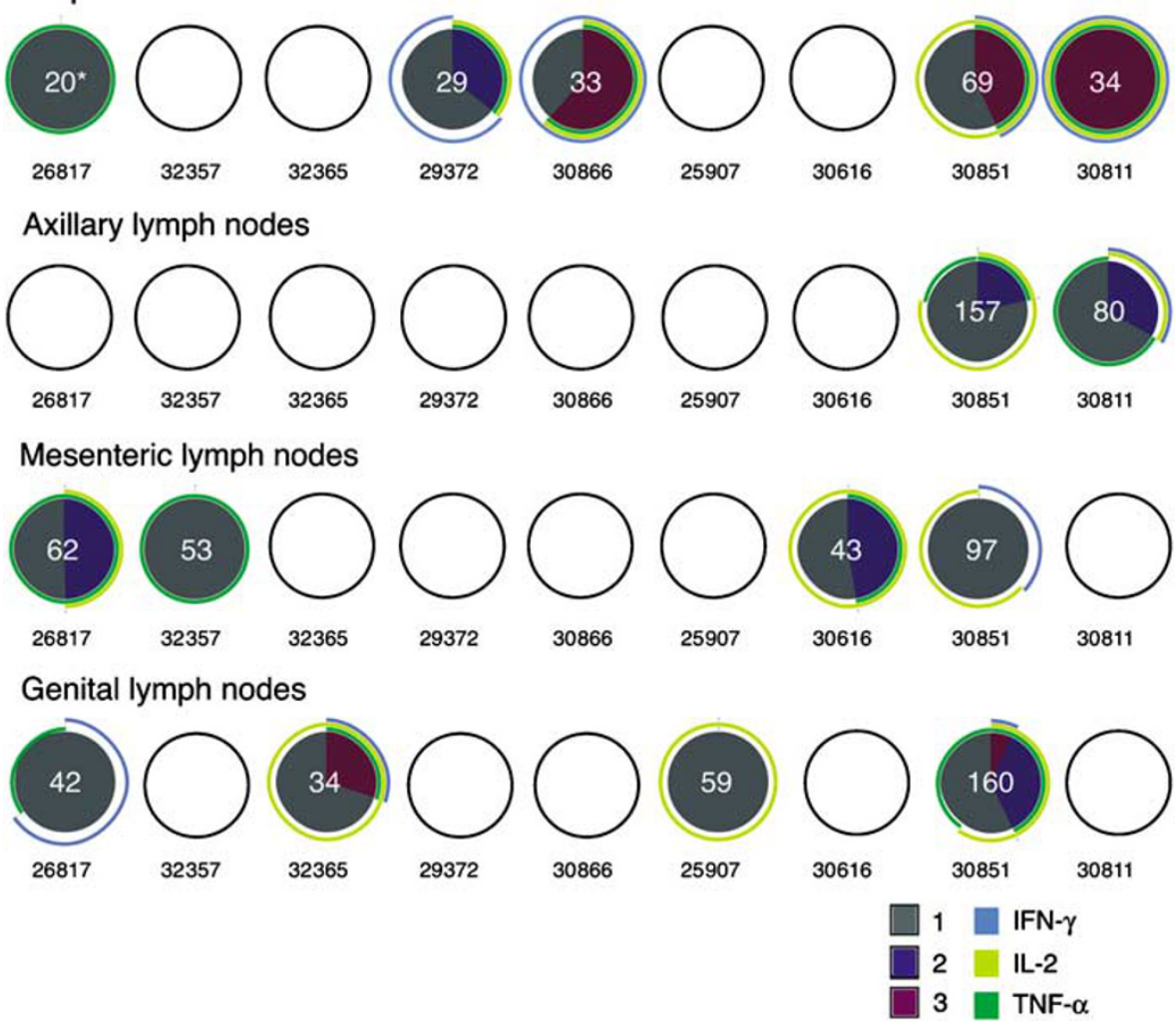

Figure 6 Gag-specific CD4+ T-cell responses in lymphoid tissues and blood of SHIV89.6-immunized rhesus macaques. SIV-specific CD4+ T-cell responses from cryopreserved PBMCs, axillary, mesenteric, and genital lymph node mononuclear cell samples are shown as a pie chart. For every positive response, the frequency of positive SIV-specific T cells was normalized to $10^{5} \mathrm{CD}^{+} \mathrm{T}$ cells and this value is shown in white at the center of the pie chart. Each portion of a pie chart indicates the percentage of SIV-specific T cells that responded with one, two, or three functions, and the arcs around the pie show the function or combination of functions to which the specific response corresponds (see color legend). ${ }^{*} \mathrm{Number}$ of $\mathrm{p} 27-$ specific CD4 ${ }^{+} \mathrm{T}$ cells (per $10^{5} \mathrm{CD}^{+} \mathrm{T}$ cells). IFN- $\gamma$, interferon $\gamma$; IL-2, interleukin 2; PBMC, peripheral blood mononuclear cell; SHIV, simian-human immunodeficiency virus; SIV, simian immunodeficiency virus; TNF- $\alpha$, tumor necrosis factor- $\alpha$.

the $\alpha$ chain of the CD8 molecule (natural killer cells and CD8 ${ }^{+}$ $\mathrm{T}$ cells) during chronic SIV infection results in a rapid increase in viral replication that wanes as the $\mathrm{CD} 8^{+}$lymphocytes repopulate. ${ }^{18,19}$ However, depletion of CD20 ${ }^{+} \mathrm{B}$ cells prior to SIV infection can also result in uncontrolled viral replication and rapid disease progression, even in animals with anti-SIV CD8 ${ }^{+}$ T-cell responses. ${ }^{20}$ In humans, strong $\mathrm{CD}^{+}{ }^{+} \mathrm{T}$-cell responses and specific MHC class I haplotypes are associated with control of HIV-1 replication and long-term survival. ${ }^{21-26}$ Humoral immunity is also considered a key component of effective antiHIV response, with non-neutralizing and neutralizing antibody responses apparently contributing to control of viral replication (reviewed in ref. 27). Despite these observations, the relative contribution of antibodies and effector $\mathrm{T}$ cells in controlling HIV replication is unclear. Further, studies to date in primate models have not clarified the role of $\mathrm{CD} 8^{+} \mathrm{T}$-cell responses in the protection conferred by pre-existing live attenuated lentivirus infections. ${ }^{1,28,29}$ Our results show that SIV-specific $\mathrm{CD}^{+}$ $\mathrm{T}$-cell responses are induced in the vaginal mucosa by a protective live attenuated lentivirus infection, and that these antiviral $\mathrm{T}$ cells are maintained for extended periods. The fact that these responses were not consistently detected in all animals reflects the observation that $40 \%$ of SHIV-immunized monkeys are not protected from challenge virus replication. ${ }^{3,4}$

The genital-tract SIV-specific T-cell responses were distinct from the responses in blood and other tissues in both frequency and function. For instance, T-cell responses in the vagina were characterized by little IFN- $\gamma$ secretion, while, in genital lymph nodes and peripheral blood, IFN- $\gamma$ secretion was the predominant response. Indeed, even within the two genital tract sites sampled, the consistency and nature of the SIV-specific T-cell responses were quite different, with antiviral $\mathrm{T}$-cell responses in the cervix relatively rare.

It is striking that cytolytic $\left(\mathrm{CD} 107 \mathrm{ab}^{+}\right) \mathrm{SIV}$-specific $\mathrm{CD} 4^{+} /$ $\mathrm{CD}^{-} \mathrm{T}$ cells were so consistently detected in the vagina of SHIV-immunized animals. Although the role of $\mathrm{CD} 4^{+} \mathrm{T}$ cells in viral infection is commonly attributed to helper functions, antiviral cytokine production and lytic functions have been described in herpes simplex virus type 1, Friend leukemia virus, and HIV infection. ${ }^{16,30,31} \mathrm{HIV}$-specific CD4 ${ }^{+} \mathrm{T}$-cell clones with cytolytic activity and IFN- $\gamma$ secretion have been reported, ${ }^{16}$ and $\mathrm{CD} 107^{+}$SIV-specific $\mathrm{CD} 4^{+}$T cells are found in the blood and respiratory tract of monkeys infected with attenuated SIVmac $\Delta n e f$, suggesting that these cells may play a role in 


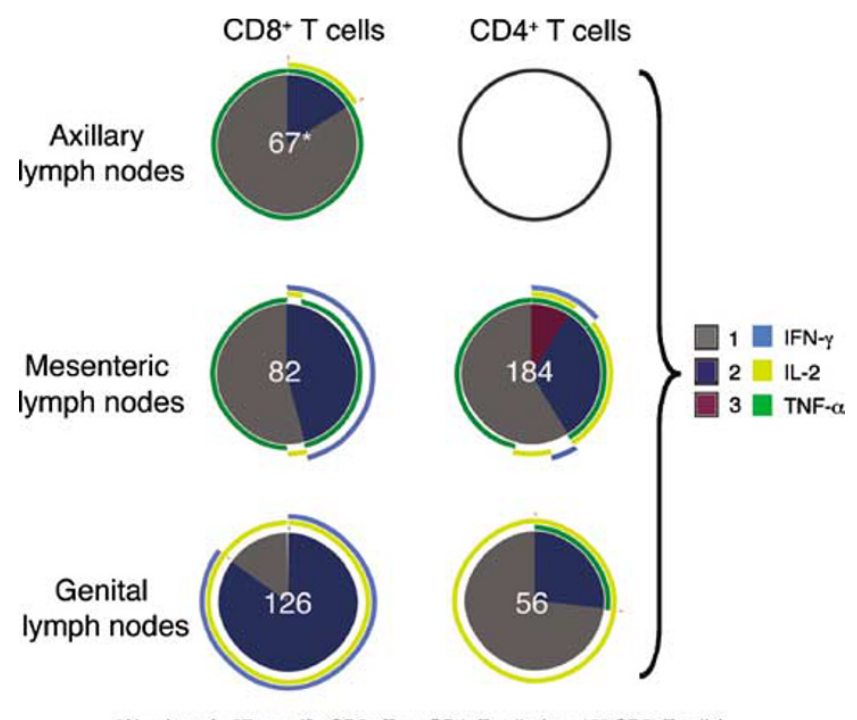

- Number of p27-specific CD8*T or CD4*T cells (per $10^{5} \mathrm{CD} 3 * \mathrm{~T}$ cells)

Figure 7 Frequency and distribution of Gag CM9-specific T cells in systemic tissues 6 months post-SHIV89.6 immunization. SIV-specific $\mathrm{CD}^{+}$and $\mathrm{CD} 4^{+} \mathrm{T}$-cell responses in cryopreserved axillary, mesenteric, and genital lymph node mononuclear cell samples from the Mamu- ${ }^{*} 01$ positive animal (30851) are shown as a pie chart (PBMC samples were not analyzed because the number of events collected was three times lower in the p27-stimulated tube relative to the background tube). An empty circle indicates lack of a positive response in that T-cell subset. The frequency of positive SIV-specific T cells normalized to $10^{5} \mathrm{CD}^{+}$ $T$ cells is shown for each individual response as a white number in the center of the pie chart. Each portion of a pie chart indicates the percentage of SIV-specific T cells that responded with one, two, or three functions, and the arcs around the pie show the function or combination of functions to which the specific response corresponds (see color legend). *Number of p27-specific CD8 ${ }^{+}$or $\mathrm{CD} 4^{+} \mathrm{T}$ cells (per $10^{5} \mathrm{CD} 3^{+}$ T cells). IFN- $\gamma$, interferon $\gamma$; IL-2, interleukin 2; PBMC, peripheral blood mononuclear cell; SHIV, simian-human immunodeficiency virus; SIV, simian immunodeficiency virus; TNF- $\alpha$, tumor necrosis factor- $\alpha$.

the protection from SIV challenge. ${ }^{32}$ Consistent with this, the SIV Gag-specific CD $4^{+} \mathrm{T}$ cells in the vaginal mucosa of SHIVimmunized animals were $\mathrm{CD} 107^{+}$and secreted IL-2. Thus, the induction of effector-memory-like $\mathrm{CD} 4^{+} \mathrm{T}$ cells in mucosal tissues might contribute to the protection in several live attenuated SIV vaccine models. Regardless of their potential contribution to protection, the SHIV89.6-induced CD4 ${ }^{+} \mathrm{T}$ cells in the vagina do not apparently increase the susceptibility of immunized animals to systemic SIV infection after vaginal SIV inoculation, a critical consideration in developing HIV vaccines.

In summary, this study shows, for the first time, that a live attenuated lentivirus infection that elicits consistent protection from vaginal SIV challenge induces cytokine-secreting and degranulating SIV Gag-specific T-cell responses in the vagina of female rhesus macaques. The antiviral T-cell responses in the vagina were maintained for 6-8 months after the attenuated virus infection. Vaginal T-cell responses were maintained in the animal that had persistent replication of the vaccine virus and in the Mamu- $\mathrm{A}^{\star} 01^{+}$animal that had undetectable vaccine virus in tissues. Thus, persistent viral replication and antigen production is not the only explanation for the long-term maintenance of these effector $\mathrm{T}$ cells in the vagina. Studies are needed to confirm the role of vaginal $\mathrm{CD} 8^{+} \mathrm{T}$ cells as an immunologic correlate of protection, but the results reported here imply that antiviral CD ${ }^{+} \mathrm{T}$ cells in the vaginal mucosa are highly desirable in an HIV vaccine designed to control heterosexual HIV transmission.

\section{METHODS}

Animals and immunization. Female rhesus macaques (Macaca mulatta) were housed at the California National Primate Research Center in accordance with the American Association for Accreditation of Laboratory Animal Care standards. The experiments were approved by the Institutional Animal Use and Care Committee of the University of California, Davis. All animals were negative for antibodies to HIV-2, SIV, type-D retrovirus, and simian T-cell lymphotropic virus type 1 at the time the study was initiated. Nine animals were IV infected with a previously described live, virulence-attenuated SHIV 89.6, ${ }^{4}$ and 6-8 months after immunization, the monkeys were necropsied.

Tissue collection and RNA isolation. Blood, vagina, cervix, spleen, jejunum, colon, and axillary, mesenteric and genital (obturator/iliac) lymph node samples were collected immediately after necropsy. Tissue samples were stored in RNAlater (Ambion, Austin, TX) at $-20^{\circ} \mathrm{C}$ until RNA extraction. This process removed any adherent mucus from the tissue samples. Prior to RNA isolation, the tissue samples were homogenized by use of a Power homogenizer ( $7 \mathrm{~mm} \times 195 \mathrm{~mm}$; Fisher Scientific, Pittsburgh, PA). The total RNA was isolated by the use of Trizol (Invitrogen, Grand Island, NY) according to the manufacturer's protocol. The organic phase was saved and stored at $-80^{\circ} \mathrm{C}$ for subsequent DNA isolation. The quantitative branched DNA assay was used to determine vRNA levels in total tissue RNA.

In addition, mononuclear cell suspensions were prepared from lymph nodes as previously described ${ }^{10}$ and PBMCs were isolated from heparinized blood using Lymphocyte Separation Medium (ICN Biomedicals, Aurora, OH). PBMC samples were frozen in 10\% DMSO (Sigma, St Louis, MO)/90\% fetal bovine serum (Gemini BioProducts, Calabasas, CA) and stored in liquid nitrogen until future analysis in immunological assays. ${ }^{3}$

Isolation of lymphocytes from the cervix and vaginal mucosa. At necropsy, fresh cervix and vagina were collected in complete RPMI-1,640

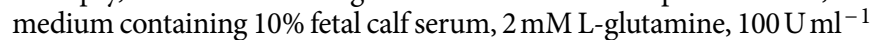
penicillin, $0.1 \mathrm{mg} \mathrm{ml}^{-1}$ streptomycin, and $1 \%$ amphotericin B (Sigma), and lymphocytes were isolated from genital mucosal tissues as previously described. ${ }^{8,12}$

Virus load measurement. Plasma and tissue RNA samples were analyzed for vRNA by a quantitative branched DNA assay. ${ }^{33}$ Virus load in plasma samples is reported as vRNA copy number per ml of plasma and, in tissue, as vRNA copy number per $\mu \mathrm{g}$ of total tissue RNA. The detection limit of this assay is $125 \mathrm{vRNA}$ copies per ml plasma. As reported previously, ${ }^{10}$ a cutoff of 200 copies per $\mu$ g tissue RNA was established based on analyses of RNA from tissues of SIV-naive rhesus macaques.

MHC class I haplotyping by PCR. MHC haplotyping (Table 1) was performed by the Rhesus Macaque MHC Typing Core, University of Wisconsin Hospital and Clinics.

SIV-specific IFN- $\gamma$ enzyme-linked immune spot assay. As described previously, ${ }^{4,34}$ the number of IFN- $\gamma$-secreting cells in cryopreserved cells in response to incubation with an SIVmac239 Gag p27 peptide pool was determined using an IFN- $\gamma$ enzyme-linked immune spot kit (U-CyTech, Utrecht University, Utrecht, The Netherlands).

Flow cytometric analysis of cell populations in PBMCs. Blood was collected at frequent intervals, and the percentages of $\mathrm{CD}^{+}{ }^{+} \mathrm{CD} 4^{+}$ 
T cells and $\mathrm{CD}^{+}{ }^{+} \mathrm{CD} 8{ }^{+} \mathrm{T}$ cells within the lymphocyte populations were determined by flow cytometric analysis using a FACSCalibur (Becton Dickinson Immunocytometry Systems, Milpitas, CA) and rhesus macaque-reactive antibodies (Pharmingen/Becton Dickinson, San Diego, CA; anti-CD3 clone no. SP34, anti-CD4 clone no. M-T477, and anti-CD8 clone no. SK1).

Intracellular staining. One million freshly isolated mononuclear cells from cervix and vagina were independently incubated with antiCD28 and anti-CD49d antibodies $\left(1 \mu \mathrm{g} \mathrm{ml}^{-1}\right.$ final concentration; BDBiosciences, San Jose, CA) as costimulatory molecules, in a total volume of $200 \mu \mathrm{l}$ complete RPMI-1,640/10\% fetal calf serum. In all the experiments, the following samples were prepared: p27 Gag peptide pool at $5 \mu \mathrm{g} \mathrm{ml}^{-1}$, background controls containing costimulatory molecules and DMSO, and a positive control stimulated with staphylococcal enterotoxin B (SEB; $0.2 \mu \mathrm{g} \mathrm{ml}^{-1}$, Sigma). A mixture of anti-CD107a and anti-CD107b-FITC antibodies (clones H4A3 and H4B4 respectively; BDPharmingen) was added to $5 \times 10^{5}$ cells at a pre-titrated volume. Cells were incubated for $6 \mathrm{~h}$ at $37^{\circ} \mathrm{C}$ in the presence of Brefeldin-A (Sigma) and monensin (GolgiStop; BD Biosciences). Following incubation, cells were washed and surface stained with anti-CD3-Pacific Blue, anti-CD4PerCP-Cy5.5, and anti-CD8-APC-Cy7. A marker to exclude dead cells, 7-aminoactinomycin D (7-AAD; Molecular Probes, Eugene, OR), was added; then samples were fixed ( $1 \%$ paraformaldehyde), permeabilized ( $0.5 \%$ saponin), and stained intracellularly with IFN- $\gamma$-APC (clone B27), TNF- $\alpha$-PE-Cy7 (clone Mab11), IL-2-PE (clone MQ1-17H12) for $20 \mathrm{~min}$ at room temperature. All monoclonal antibodies were from Pharmingen/ Becton-Dickinson, unless specified. After washing with permeabilizing buffer, cells were fixed in phosphate-buffered saline (PBS) containing $1 \%$ paraformaldehyde.

For intracellular staining of PBMCs, axillary, mesenteric, and genital lymph nodes, a slight modification of a previously reported protocol was used. ${ }^{13}$ Frozen samples were thawed and rested overnight at $37^{\circ} \mathrm{C}$, in $5 \%$ $\mathrm{CO}_{2}$ atmosphere, in AIM V media (Invitrogen Inc, Grand Island, NY) containing $20 \%$ fetal calf serum. The next day, the cells were adjusted to $1 \times 10^{6}$ per $200 \mu \mathrm{l}$, and stimulated and stained in the same manner as for the genital tract mononuclear cells, except that an anti-HLA-DR-FITC $\mathrm{mAb}$ was substituted for the anti-CD107ab-FITC $\mathrm{mAb}$ in the second panel. The rest of the procedures were as explained above.

Data were acquired using a FACSAria flow cytometer (Becton Dickinson) and analyzed using FlowJo software (Treestar, Ashland, OR) and a Macintosh G5 computer (Apple, Cupertino CA). At least 100,000 events in the forward vs. side scatter (FSC/SSC) lymphocyte gate were acquired for all tissues except genital tract. As noted in the results, due to the low frequency of $\mathrm{T}$ cells in genital tract tissues, all the detectable lymphocyte events in a sample were collected. The background level of cytokine staining varied from sample to sample, but was typically $<0.05 \%$ of the unstimulated $\mathrm{CD} 8^{+} \mathrm{T}$ lymphocytes. The only samples considered positive were those in which, after subtracting the DMSO background control, there were at least five positive events for a single functional marker, three positive events for two or more simultaneous functional markers, and the sum of the different combinations of responses represented at least 10 events. In addition, a sample was not considered positive for a particular combination of functions if the frequency of responding $\mathrm{T}$ cells with that particular combination of functions was lower than $0.02 \%$. All data are reported after subtraction of the DMSO-medium control cultures. The SPICEv4.1.5 and PESTLEv1.5.2 software programs (a gift from M. Roederer, Vaccine Research Center, NIAID/NIH) were used to create the pie charts that represent each individual response.

In situ tetramer staining. In situ tetramer staining was performed essentially as previously described. ${ }^{35,36}$ Fresh lymph nodes, spleen, vaginal and cervical tissues were shipped on ice in RPMI with sodium heparin $\left(18.7 \mathrm{U} \mathrm{ml}^{-1}\right.$ ) over night from the California National Primate Research Center to the University of Minnesota. Biotinylated Mamu$\mathrm{A}^{\star} 01 / \mathrm{B} 2 \mathrm{~m} /$ peptide molecules were produced with Gag (CTPYDINQM) (Beckamn-Coulter Immunomics, Hialeah, FL) or negative control irrelevant (FLPSDYFPSV) peptides (NIH tetramer facility). Tetramers were generated by adding six aliquots of FITC-labeled ExtraAvidin (Sigma) to biotinylated $M a m u-A^{\star} 01 / B 2 m /$ peptide monomers over the course of $8 \mathrm{~h}$ to a final molar ratio of $4.5: 1$. Tissues were cut into $0.5-\mathrm{cm}$ pieces and embedded in warm PBS-buffered $4 \%$ low-melt agarose, cut into blocks, and glued to a vibratome cutting platform. Tissue blocks were placed in a vibratome bath containing $0-4^{\circ} \mathrm{C}$ PBS containing $100 \mu \mathrm{g} \mathrm{ml}^{-1}$ heparin (PBS-H) and sectioned. Two hundred- $\mu \mathrm{m}$ thick fresh sections were stained free floating in $1 \mathrm{ml}$ of solution in tissue chambers placed in 24-well tissue culture plates. Incubations were carried out at $4^{\circ} \mathrm{C}$ on a rocking platform. Tetramers were added at a concentration of $0.5 \mathrm{mg} \mathrm{ml}^{-1}$ with $2 \%$ normal goat serum (NGS) and $0.5 \mathrm{mg} \mathrm{ml}^{-1}$ mouse anti-human CD8 mAb (Dako, Carpenteria, CA; clone DK25) diluted in PBS-H and incubated overnight. Sections were washed with chilled PBS-H and then fixed with $4 \%$ paraformaldehyde for $2 \mathrm{~h}$ at room temperature. Sections were again washed with $\mathrm{PBS}-\mathrm{H}$, incubated with rabbit anti-FITC antibodies (BioDesign International, Kennebunkport, MA) diluted 1:10,000 in PBS-H with $2 \%$ normal goat serum, and incubated for 1-3 days. Sections were washed three times with PBS-H for at least $20 \mathrm{~min}$ and then incubated with Cy3-conjugated goat anti-rabbit $\mathrm{mAb}$ diluted 1:5,000 (Jackson ImmunoResearch, West Grove, PA) and Alexa 488-conjugated goat anti-mouse mAb diluted 1:2,000 (Molecular Probes) in PBS-H with $2 \%$ normal goat serum, for 1-3 days. Finally, sections were washed three times for at least $20 \mathrm{~min}$ in $\mathrm{PBS}-\mathrm{H}$, post-fixed with $4 \%$ paraformaldehyde for $1 \mathrm{~h}$, and then mounted on slides with warmed glycerol gelatin (Sigma) containing $4 \mathrm{mg} \mathrm{ml}^{-1} n$-propyl galate. Stained sections were analyzed using a confocal microscope. Digital images were processed using confocal assistant version 4.02 (Todd Brelje) and Adobe Photoshop 7.01.

Flow cytometry tetramer staining. Fresh mononuclear cells from the vaginal mucosa or cryopreserved PBMCs and lymph node mononuclear cells $\left(1 \times 10^{6}\right.$ cells $)$ were stained with $5 \mu \mathrm{l}\left(0.1 \mathrm{mg} \mathrm{ml}^{-1}\right)$ of a pre-titrated stock of the Mamu-A ${ }^{\star} 01$ tetramers $\mathrm{Gag}_{181-189} \mathrm{CM} 9$ (CTPYDINQM), Tat $_{28-35}$ SL8 (STPESANL), Gag ${ }_{340-349}$ VT10 (VNPTLEEMLT), and Env $_{620-628}$ TL9 (TVPWPNASL), all conjugated to allophycocyanin (APC) (a generous gift from D. Watkins). After $1 \mathrm{~h}$ incubation at $37^{\circ} \mathrm{C}$, cells were stained for an additional $45 \mathrm{~min}$ at room temperature with surface markers, using a cocktail containing pre-titrated amounts of the following mAbs (all from BD Biosciences): CD3-FITC (clone SP34), CD4-PE (clone L200), and CD8-PerCP (clone SK1). Samples were washed twice with FACS wash buffer, red blood cells were lysed, and cells fixed and stabilized with paraformaldehyde using a Coulter TQ-prep (Coulter, Hialeah, FL). PBMCs from Mamu-A ${ }^{\star} 01$-positive and uninfected macaques were used as positive and negative controls, respectively. Sample data were acquired on a FACSCalibur (BD Biosciences, Mountain View, CA) and analyzed using FlowJO software (BD Immunocytometry Systems). Positive tetramer responses were defined as the percentage of $\mathrm{CD}^{+}{ }^{+} \mathrm{CD} 8{ }^{+} \mathrm{T}$ cells, which represented three times the mean percentage observed in background samples (without tetramer), and with a minimum of 10 positive events after background subtraction.

Statistical analyses. Statistics are reported as the mean and the standard error of the mean for each group using Prism 4.0 software (GraphPad Software, San Diego, CA).

\section{ACKNOWLEDGMENTS}

We thank M. Busch, Keith Reimann, and Nancy Miller for helpful discussion, the Primate Services Unit at the CNPRC Lili Guo, and Roxana Colon for excellent technical assistance. We also thank Dr Roederer, National Institutes of Health Vaccine Research Center, for providing the SPICE and PESTLE software, and Dr Watkins, University of Wisconsin, for providing the $\mathrm{MHC}$ peptide tetramers complexes. This work was supported by Public Health Services grants U51RR00169, from the National Center for Research Resources; and P01 Al066314 and R01 Al44480 from the National Institute of Allergy and Infectious Diseases and a gift from the James B Pendleton Charitable Trust. 


\section{DISCLOSURE}

The authors declared no conflict of interest.

(C) 2008 Society for Mucosal Immunology

\section{REFERENCES}

1. Koff, W.C. et al. HIV vaccine design: insights from live attenuated SIV vaccines. Nat. Immunol. 7, 19-23 (2006).

2. Johnson, R.P. \& Desrosiers, R.C. Protective immunity induced by live attenuated simian immunodeficiency virus. Curr. Opin. Immunol. 10, 436-443 (1998).

3. Miller, C.J. et al. Rhesus macaques previously infected with simian/human immunodeficiency virus are protected from vaginal challenge with pathogenic SIVmac239. J. Virol. 71, 1911-1921 (1997).

4. Abel, K. et al. Simian-human immunodeficiency virus SHIV89.6-induced protection against intravaginal challenge with pathogenic SIVmac239 is independent of the route of immunization and is associated with a combination of cytotoxic T-lymphocyte and alpha interferon responses. J. Virol. 77, 3099-3118 (2003).

5. Miller, C.J. \& Lu, F.X. Anti-HIV and -SIV immunity in the vagina. Int. Rev. Immunol. 22, 65-76 (2003).

6. Miller, C.J., McChesney, M. \& Moore, P.F. Langerhans cells, macrophages and lymphocyte subsets in the cervix and vagina of rhesus macaques. Lab. Invest. 67, 628-634 (1992).

7. Lohman, B.L., Miller, C.J. \& McChesney, M.B. Antiviral cytotoxic T lymphocytes in vaginal mucosa of simian immunodeficiency virus-infected rhesus macaques. J. Immunol. 155, 5855-5860 (1995).

8. Reynolds, M.R. et al. CD8+ T-lymphocyte response to major immunodominant epitopes after vaginal exposure to simian immunodeficiency virus: too late and too little. J. Virol. 79, 9228-9235 (2005).

9. Musey, L. et al. HIV-1 induces cytotoxic T lymphocytes in the cervix of infected women. J. Exp. Med. 185, 293-303 (1997).

10. Miller, C.J. et al. Propagation and dissemination of infection after vaginal transmission of simian immunodeficiency virus. J. Virol. 79, 9217-9227 (2005).

11. Lu, Y. et al. Vaginal transmission of chimeric simian/human immunodeficiency viruses in rhesus macaques. J. Virol. 70, 3045-3050 (1996).

12. Lu, F.X. et al. The strength of $B$ cell immunity in female rhesus macaques is controlled by CD8+ T cells under the influence of ovarian steroid hormones. Clin. Exp. Immunol. 128, 10-20 (2002).

13. Genesca, M. et al. Live attenuated lentivirus infection elicits polyfunctional simian immunodeficiency virus Gag-specific CD8+ T cells with reduced apoptotic susceptibility in rhesus macaques that control virus replication after challenge with pathogenic SIVmac239. J. Immunol. 179, 4732-4740 (2007).

14. Pahar, B., Lackner, A.A. \& Veazey, R.S. Intestinal double-positive CD4+CD8+ T cells are highly activated memory cells with an increased capacity to produce cytokines. Eur. J. Immunol. 36, 583-592 (2006).

15. Kuroda, M.J. et al. Analysis of Gag-specific cytotoxic T lymphocytes in simian immunodeficiency virus-infected rhesus monkeys by cell staining with a tetrameric major histocompatibility complex class I-peptide complex. J. Exp. Med. 187, 1373-1381 (1998).

16. Norris, P.J. et al. Multiple effector functions mediated by human immunodeficiency virus-specific CD4(+) T-cell clones. J. Virol. 75, 9771-9779 (2001).
17. Rollman, E. et al. Killing kinetics of simian immunodeficiency virus-specific CD8+ T cells: implications for HIV vaccine strategies. J. Immunol. 179, 4571-4579 (2007)

18. Schmitz, J.E. et al. Control of viremia in simian immunodeficiency virus infection by CD8+ lymphocytes. Science 283, 857-860 (1999).

19. Jin, X. et al. Dramatic rise in plasma viremia after CD8(+) T cell depletion in simian immunodeficiency virus-infected macaques. J. Exp. Med. 189, 991-998 (1999).

20. Miller, C.J. et al. Antiviral antibodies are necessary for control of simian immunodeficiency virus replication. J. Virol. 81, 5024-5035 (2007).

21. Gea-Banacloche, J.C. et al. Maintenance of large numbers of virusspecific CD8+ T cells in HIV-infected progressors and long-term nonprogressors. J. Immunol. 165, 1082-1092 (2000).

22. Migueles, S.A. et al. HLA $B^{\star} 5701$ is highly associated with restriction of virus replication in a subgroup of HIV-infected long term nonprogressors. Proc. Natl. Acad. Sci. USA 97, 2709-2714 (2000)

23. Frater, A.J. et al. Effective T-cell responses select human immunodeficiency virus mutants and slow disease progression. J. Virol. 81, 6742-6751 (2007).

24. Goulder, P.J. et al. Late escape from an immunodominant cytotoxic T-lymphocyte response associated with progression to AIDS. Nat. Med. 3, 212-217 (1997)

25. Altfeld, M.A. et al. Identification of novel HLA-A2-restricted human immunodeficiency virus type 1-specific cytotoxic T-lymphocyte epitopes predicted by the HLA-A2 supertype peptide-binding motif. J. Virol. 75, 1301-1311 (2001)

26. Betts, M.R. et al. HIV nonprogressors preferentially maintain highly functional HIV-specific CD8+ T cells. Blood 107, 4781-4789 (2006).

27. Huber, M. \& Trkola, A. Humoral immunity to HIV-1: neutralization and beyond. J. Int. Med. 262, 5-25 (2007).

28. Stebbings, R. et al. Mechanisms of protection induced by attenuated simian immunodeficiency virus. II. Lymphocyte depletion does not abrogate protection. AIDS Res. Hum. Retroviruses 14, 1187-1198 (1998).

29. Matano, T. et al. Administration of an anti-CD8 monoclonal antibody interferes with the clearance of chimeric simian/human immunodeficiency virus during primary infections of rhesus macaques. J. Virol. 72, 164-169 (1998).

30. Doymaz, M.Z., Foster, C.M., Destephano, D. \& Rouse, B.T. MHC IIrestricted CD4+ cytotoxic T lymphocytes specific for herpes simplex virus-1: implications for the development of herpetic stromal keratitis in mice. Clin. Immunol. Immunopathol. 61, 398-409 (1991).

31. Hasenkrug, K.J., Brooks, D.M. \& Dittmer, U. Critical role for CD4(+) T cells in controlling retrovirus replication and spread in persistently infected mice. J. Virol. 72, 6559-6564 (1998).

32. Gauduin, M.C. et al. Induction of a virus-specific effector-memory CD4+ T cell response by attenuated SIV infection. J. Exp. Med. 203, 2661-2672 (2006).

33. Dailey, P.J., Zamroud, M., Kelso, R., Kolberg, J. \& Urdea, M. Quantitation of simian immunodeficiency virus (SIV) RNA in plasma of acute and chronically infected rhesus macaques using a branched DNA (bDNA) signal amplification assay. J. Med. Primatol. 24, 209 (1995).

34. Pahar, B., Li, J., Rourke, T., Miller, C.J. \& McChesney, M.B. Detection of antigen-specific $T$ cell interferon gamma expression by ELISPOT and cytokine flow cytometry assays in rhesus macaques. J. Immunol. Methods 282, 103-115 (2003).

35. Skinner, P.J., Daniels, M.A., Schmidt, C.S., Jameson, S.C. \& Haase, A.T. Cutting edge: in situ tetramer staining of antigen-specific T cells in tissues. J. Immunol. 165, 613-617 (2000).

36. Skinner, P.J. \& Haase, A.T. In situ tetramer staining. J. Immunol. Methods 268, 29-34 (2002). 